Article

\title{
An Analysis of Ku-Band Profiling Radar Observations of Boreal Forest
}

\author{
Livia Piermattei ${ }^{1, *}$, Markus Hollaus ${ }^{1}$, Milutin Milenković ${ }^{1}$ (i), Norbert Pfeifer ${ }^{1}$ (D), \\ Raphael Quast ${ }^{1}$, Yuwei Chen ${ }^{2}$, Teemu Hakala ${ }^{2}$ (D), Mika Karjalainen ${ }^{2}$ (D), Juha Hyyppä ${ }^{2}$ \\ and Wolfgang Wagner ${ }^{1}$ \\ 1 Department of Geodesy and Geoinformation (GEO), Technische Universität Wien, 1040 Vienna, Austria; \\ Markus.Hollaus@geo.tuwien.ac.at (M.H.); Milutin.Milenkovic@geo.tuwien.ac.at (M.M.); \\ Norbert.Pfeifer@geo.tuwien.ac.at (N.P.); raphael.quast@geo.tuwien.ac.at (R.Q.); \\ Wolfgang.Wagner@geo.tuwien.ac.at (W.W.) \\ 2 Department of Remote Sensing and Photogrammetry, Finnish Geospatial Research Institute, \\ 02431 Kirkkonummi, Finland; yuwei.chen@maanmittauslaitos.fi (Y.C.); teemu.hakala@nls.fi (T.H.); \\ mika.karjalainen@nls.fi (M.K.); juha.hyyppa@nls.fi (J.H.) \\ * Correspondence: livia.piermattei@geo.tuwien.ac.at; Tel.: +43-1-588-011-2257
}

Received: 20 September 2017; Accepted: 30 November 2017; Published: 2 December 2017

\begin{abstract}
Radar sensors have the potential to retrieve vertical forest structure measurements thanks to their capability to penetrate into the foliage. However, studies are needed in order to understand better the interaction of radar beams with the canopy. The most commonly used radar technique for estimating forest parameters operates from spacecraft at different wavelength ( $X_{-}, C_{-}$, and L-band). In order to assist in the interpretation of satellite data for forest applications, and as a possible complementary technique to Lidar (Light detection and ranging), the Finnish Geospatial Research Institute has developed the first helicopter-borne profiling radar system operating in Ku-band, called Tomoradar, which is able to provide a vertical canopy profile. The study focuses on the analyses of Ku-band profiling radar waveforms and the backscatter signal of boreal forest, supported by simultaneously acquired Lidar measurements, in order to detect ground and canopy profiles and quantify the ground echo ratio under different canopy coverage and the backscatter signal variation through the vegetation. The Tomoradar data was acquired simultaneously with a lightweight Velodyne VLP-16 Lidar system in October 2016 over a boreal forest located in Evo in southern Finland. Additionally, highly accurate Riegl VQ-480 Lidar data, acquired in 2014, was used as a ground reference for both lightweight systems. We analysed the co- and cross-polarized (HH and HV) Tomoradar backscatter signals of a $600 \mathrm{~m}$ long profile. It is found that the Ku-band Tomoradar penetrates the canopy to a similar extent as the Velodyne Lidar, i.e., the distribution of backscatter signals through the vegetation follows the vegetation density. Moreover, the ground backscatter signal strength and ground echo ratio depend strongly on the presence of gaps in the canopy. By comparing the elevation of the corresponding canopy and ground Tomoradar signal peaks with the Velodyne Lidar data, the Tomoradar ground elevation accuracy is on average $-0.03 \mathrm{~m}$ and $-0.20 \mathrm{~m}$ for the cross- and co-polarization, respectively, whereas the bias of the canopy elevation is, on average, $-0.58 \mathrm{~m}$ and $1.35 \mathrm{~m}$ for the cross- and co-polarization, respectively. With respect to the ground height data derived from the Lidar measurements of 2014, the Tomoradar ground profile reveals, on average, higher accuracy (i.e., $0.00 \mathrm{~m}(\sigma=0.41 \mathrm{~m})$ and $0.04 \mathrm{~m}(\sigma=0.37 \mathrm{~m})$ for the co-and cross-polarizations, respectively) than the Velodyne system $(-0.37 \mathrm{~m}$ with $\sigma=0.25 \mathrm{~m})$.
\end{abstract}

Keywords: Ku-band; backscatter; boreal forest; profiling radar; Lidar 


\section{Introduction}

Knowledge about spatial and temporal changes of the forest structure is an essential component in forest management and ecology [1]. Forest structure includes the canopy vertical structure and geometry (e.g., size, height, and shape), tree position, and species [2,3]. The estimation of these components allows us to define many other forest attributes of broad ecological interest, such as stem diameter, basal area, biomass, timber volume, and forest density. Moreover, monitoring forest structure changes over time contributes to ecologically oriented studies in terms of carbon allocation and forest expansion.

Inventories and monitoring programs are periodically carried out and updated at both regional and country levels to estimate carbon stored in forest stands and its accumulation over time and space. Such studies are possible thanks to large-scale data collection and analyses. Over the last few decades, remotely sensed data has been widely acknowledged as essential to derive forestry variables on a large scale. The technological capabilities of active remote sensing devices, such as their ability to penetrate the vegetation, promoted extensive use of Lidar (Light detection and ranging) and the radar system for forest surveyance [4-6].

Lidar from aircraft currently represents the primary remote sensing technique for deriving forest structure information on a regional scale. However, the advantages of radar technique like independence of weather condition, large coverage, and high penetration into the canopy motivate researchers to use radar data to predict forest information.

Synthetic Aperture Radar (SAR) imaging is the most commonly used radar technique for estimation of forest parameters, and it operates from airborne platforms and spacecraft at different frequency bands. The most common spaceborne SAR systems used for forest applications operate at short wavelength $X-(\lambda \sim 3 \mathrm{~cm}), C-(\lambda \sim 5 \mathrm{~cm})$, and L-band $(\lambda \sim 24 \mathrm{~cm})$, but also longer wavelengths (P-band) are increasingly used in vegetation studies [7]. In fact, ESA's upcoming forest mission BIOMASS is being designed to provide P-band spaceborne SAR measurements to determine the amount of biomass and carbon stored in forests. Most of the research exploiting SAR for forest mapping purposes has focused on large-scale forest classification [8] or canopy height model reconstruction using interferometric techniques $[9,10]$. Recent studies have shown that elevation information extracted from SAR has potential in the estimation of forest canopy height, even close to Lidar data (e.g., [8,11,12]). Only recently, the very first investigations toward single-tree recognition in airborne SAR data have been introduced [13]. With spaceborne SAR, the confounding signals coming from the forest floor cannot be separated from the total SAR signal, and, in particular, the vertical canopy structure information is missing. Since radar techniques provide penetration into the foliage, vertical radar profiles should be studied in order to better understand the interaction of radar beams with the canopy.

For assisting the interpretation of satellite data and as a possible complementary technique to Lidar, the Finnish Geospatial Research Institute (FGI) designed a helicopter-borne Frequency Modulated Continuous Wave (FMCW) profiling radar system, called Tomoradar. A Ku-band was adopted in order to test a short wavelength $(14 \mathrm{GHz}, \lambda \sim 2.1 \mathrm{~cm})$ over a boreal forest and to reduce the size and weight of the system. Moreover, the current frequency selection represents a trade-off between technical and financial parameters. The system is composed of two separated parabolic antennas with a size of around $33 \mathrm{~cm}$ that provide co- and cross-polarization modes for a total weight of less than $5 \mathrm{~kg}$. Currently, Ku-band is employed for measuring oceanic surface wind, ice sheet, and snow-pack, from spaceborne-borne Ku-band scatterometers (e.g., SASS (14.6 GHz), NSCAT (14.0 GHz), and Seawind (13.4 GHz)) and ground based SAR [14,15]. A Ku-band satellite mission, called Cold Regions Hydrology High-resolution Observatory $\left(\mathrm{CoRe}-\mathrm{H}_{2} \mathrm{O}\right)$, was proposed to ESA for spatially improving the observations of snow and ice in climate research [16], without success.

To the best of our knowledge, the Tomoradar is the only Ku-band radar profiling system designed for forest applications. Previously, the Helsinki University of Technology developed the C-band and X-band helicopter-borne HUTSCAT scatterometer [17], for forest mapping, which was able to collect a vertical backscattering profile along the flight track. Similar to HUTSCAT, the radiation of the 
Tomoradar penetrates through the vegetation, recording a canopy-penetrating profile of the forest. Vertical polarimetric backscatter canopy profiles were also analysed by [18] with a C-band ground tomographic profiling.

For assisting modelling of radar signals with forest canopies, FGI selected a boreal forest located in Evo in southern Finland, and in October 2016 they acquired simultaneously Tomoradar and Lidar data using a lightweight Velodyne system. Additionally, high-accuracy Riegl VQ-480 Lidar data, acquired in 2014, was used as a ground reference for both lightweight systems. Information about the Tomoradar system was published by [19]. Noting that the Ku-band wavelength is comparable to the size of needles and twigs, we hypothesize that (1) the signal is dominated by echoes from needles and twigs, (2) the waveform profile strongly depends on the 3D canopy structure, and (3) the penetration is driven primarily by geometric gaps in the canopy. To verify these hypotheses, we analysed the coand cross-polarized ( $\mathrm{HH}$ and $\mathrm{HV}$ ) Tomoradar backscatter signals of a $600 \mathrm{~m}$ long profile of boreal forest. The analyses focus on the profiling radar waveforms and backscatter signal, with the support of simultaneously acquired Velodyne Lidar measurements in order to quantify (i) the ground echo ratio under different canopy coverage and its correlation with canopy gaps and canopy height, and (ii) the backscatter signal variation through the vegetation according to the vegetation density. We developed a signal processing method to automatically detect the backscatter signals from the ground and canopy (i.e., upper crown height of dominant plants within the Tomoradar antenna's footprint) and derive their energy. To validate our approach, we estimated the accuracy of the corresponding canopy and ground elevation of the Tomoradar signal peak and the canopy height with the Lidar measurements.

\section{Materials and Methods}

\subsection{Study Site}

The study site (Figure 1a) is part of a boreal forest region in southern Finland (Evo, $61^{\circ} 19^{\prime} \mathrm{N}$, $25^{\circ} 11^{\prime} \mathrm{E}$ ). The area was chosen in order to analyse the Tomoradar backscatter signals from different vegetation density, tree height (i.e., age), and species. Forest species composition includes scots pine (Pinus sylvestris), Norway spruce (Picea abies), and birch (Betula sp.). The Tomoradar and Lidar systems were mounted on a Bell-206 helicopter and collected simultaneously on September 2016. Their installation on the helicopter is illustrated in Figure $1 \mathrm{~b}$. The total length of the helicopter flight line over the test area was around $60 \mathrm{~km}$. In the Figure 1a, the helicopter's trajectory during the test is presented, which was measured using the global navigation satellite system and a tactical-grade inertial measurement unit (GNSS-IMU), which operates at a centimetre accuracy level. In this study, a $600 \mathrm{~m}$ profile was investigated (the red solid line in Figure 1a).

\subsection{Tomoradar Data}

The helicopter-borne Tomoradar system is a light-weight profiling radar with dual-antenna configuration (transmitting and receiving antenna) in Ku-band. The size of two antennas is less than $70 \mathrm{~cm}$ with field of view (FOV) of $6^{\circ}$, determined by the $3 \mathrm{~dB}$ beamwidth of the antenna. Other pertinent Tomoradar sensor parameters are provided in Table 1 , and a detailed description about the technical characteristics and data processing is provided by Chen et al. [19]. Feng et al. [20] described the calibration procedure of the Tomoradar system.

Tomoradar allows for the recoding of a set of georeferenced profiles of the investigated scenario in co- and cross-polarizations. It features a high-range resolution (along the instrumental line of sight) of $0.15 \mathrm{~m}$ (i.e., sampled signals) and an along-track sampling interval of $0.06 \mathrm{~m}$ (one waveform every $6.1 \mathrm{~cm}$ ), assuming an average speed of the helicopter of $10 \mathrm{~m} / \mathrm{s}$. Since Tomoradar is not equipped with a mechanical scanner, it records the backscatter signals only at nadir direction along the trajectory with a few meters swath width. The backscatter signal strength expressed in decibel (dB) originates from the observed area defined by the instrument footprint cone with a diameter of $10.5 \mathrm{~m}$ at $100 \mathrm{~m}$ flight height. 
(a)

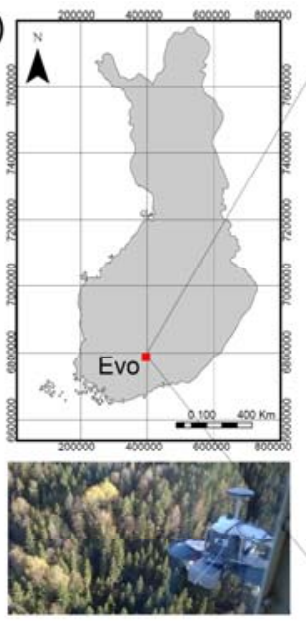

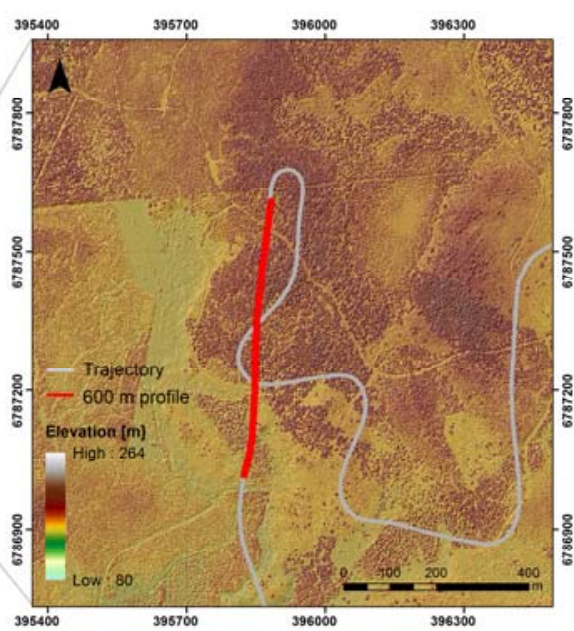

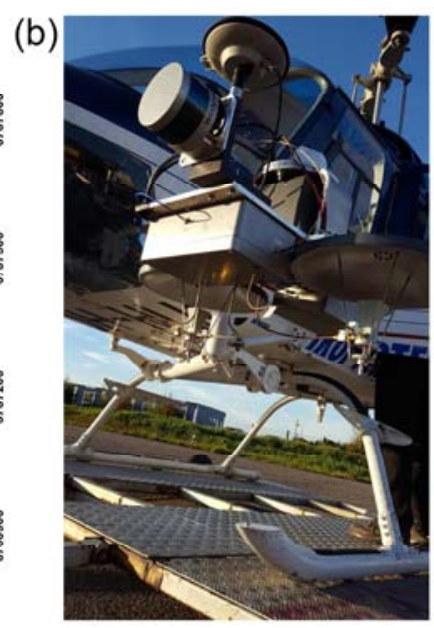

Figure 1. (a) Location map of the study site, Evo in southern Finland, the digital elevation model of the study site with the trajectory flight (grey line), and the selected $600 \mathrm{~m}$ profile (red line) and a photograph illustrating the surveyed forest with the Tomoradar; $(\mathbf{b})$ the equipment mounted on the helicopter: Tomoradar with double antenna, Velodyne VLP-16, global navigation satellite system (GNSS), and inertial measurement unit (IMU).

We analysed the co- and cross-polarized (HH and HV) Tomoradar backscatter signals of a $600 \mathrm{~m}$ long vertical profile that was chosen for the characteristics of the plot composed by vegetation with different tree heights and density, and ground with a maximum slope of $37^{\circ}$. That profile was acquired in nadir flight direction without helicopter turns that may generate blurred reflection signals, as demonstrated by Chen et al. [19]. The selected $600 \mathrm{~m}$ vertical profile, i.e., around $1 \mathrm{~min}$ of acquisition, consists of 10,002 waveforms, from which we selected 350 samples for each waveform in range direction. The diameter of the footprint at the ground is, on average, $6.8 \mathrm{~m}$, varying from a minimum $6.1 \mathrm{~m}$ to a maximum of $7.5 \mathrm{~m}$ according to the flight height that ranged between $58 \mathrm{~m}$ and $71 \mathrm{~m}$ above terrain. The flight height was chosen in order to cover the canopy of a single mature tree with the resulting footprint size.

The selected Tomoradar vertical profiles (coloured according to the backscatter signal strength) are shown in Figure 2 for both polarizations. The co-polarized backscatter signals range from $-113.46 \mathrm{~dB}$ to $-28.59 \mathrm{~dB}$ and from $-141.19 \mathrm{~dB}$ to $-45.42 \mathrm{~dB}$ for the cross-polarization, with an estimated average noise floor of $-86 \mathrm{~dB}$.

Table 1. Technical specification of Tomoradar.

\begin{tabular}{cc}
\hline \multicolumn{2}{c}{ Parameters } \\
\hline Modulation frequency & $163 \mathrm{~Hz}$ \\
Output frequency & $14 \mathrm{GHz}(2.1 \mathrm{~cm})$ \\
Range resolution $(\mathrm{m})$ & 0.15 \\
Along-track sampling interval $(\mathrm{m})$ & 0.06 \\
Spatial resolution & two-way antenna beamwidth $<6^{\circ}$ \\
Transmit receive polarizations & $\mathrm{HV} / \mathrm{HH}$ \\
Weight & Less than $5 \mathrm{~kg}$ \\
Data rate & $2.5 \mathrm{Mbits} / \mathrm{s}$ \\
\hline
\end{tabular}



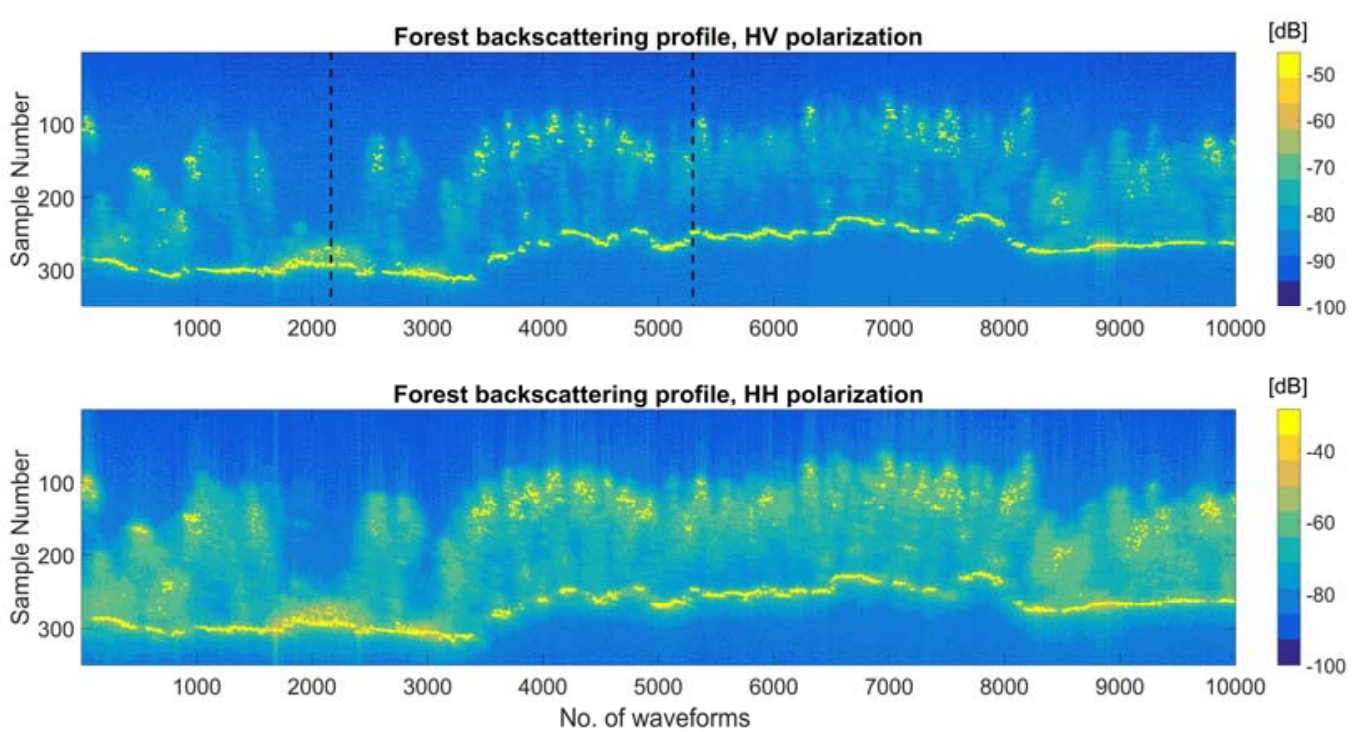

Figure 2. Cross- and co-polarized Tomoradar vertical profile of the selected $600 \mathrm{~m}$ flight line. The yellow dots represent the higher backscatter signal strength $(\mathrm{dB})$ for each waveform.

\subsection{Lidar Data}

The aim of collecting Lidar measurements is to offer a 3D point cloud over the same test area as reference for the Tomoradar observations analyses and validate the estimation of the Tomoradar ground and canopy elevation. A small, lightweight Velodyne VLP-16 was installed on the same platform as the Tomoradar system, and the data were acquired simultaneously. The Velodyne Lidar was utilized to obtain a reference 3D information of (i) ground and canopy elevation and canopy height, (ii) canopy gaps, and (iii) vegetation density of the forest surveyed with the Tomoradar.

The average point density was approximately 85 points per square meter for the selected area. In order to validate the ground measurements derived by both lightweight Lidar sensor and Tomoradar, a highly accurate Riegl VQ-480 collected in the year 2014 was additionally used. The Lidar ground points of both systems were classified using OPALS [21].

The point cloud collected by Lidar cannot be directly compared with the Tomoradar measurement, since the Lidar has a significantly smaller footprint than the Tomoradar (i.e., $0.1 \mathrm{~m}$ for Velodyne and $0.03 \mathrm{~m}$ for Riegl vs. $10.5 \mathrm{~m}$ for Tomoradar at $100 \mathrm{~m}$ altitude). Therefore, in order to compare the measurements from the two sensors, the Lidar data within each Tomoradar footprint cone were selected (Figure 3) and compared. The footprint on the ground of Tomoradar waveform was calculated as function of the range because the real range between helicopter and ground changed during the flight. For each footprint cone, we considered as reference values the mean elevation of the Lidar ground points and the maximum elevation of the Velodyne point cloud. For the Lidar measurement of 2014, only the ground points within the footprint cone were used. The Lidar canopy gaps were calculated from the Velodyne point cloud as the ratio between the number of the classified ground points and the total number of Lidar points within each Tomoradar footprint cone.

\subsection{Analyses}

We analysed the backscatter signal strength measured by Tomoradar data in order to understand the contribution from the canopy and the ground to the overall backscatter signal and the interaction of the radar beams with the canopy in terms of penetration capability. The investigation on the backscatter signal strength within the antenna's footprint was supported by the simultaneous Lidar measurements used as reference. According to the global coordinate measurements of the georeferencing system, the elevation histogram of the Lidar points from the same area observed by Tomoradar can be generated and compared with the Tomoradar waveform. The Lidar comparison allowed us to understand the 
location of the top canopy point among the canopy backscatter returns. The top of canopy and the ground point and the threshold of the ground and canopy returns were detected automatically for each waveform using signal processing. Those thresholds were used to estimate (i) the ground, (ii) canopy integrated backscatter expressed in decibel (we refer to this quantity as energy of ground and energy of canopy), and (iii) the energy of the entire waveform. The latter was used to quantify the ground echo ratio calculated as the ratio between the energy of ground and the energy of the entire waveform. The energies were calculated by summing, over all individual waveforms, the return signals in linear units in-between the identified thresholds. The ground and top of canopy points were validated with the reference lidar data, and they were used to estimate the canopy height.

(a)

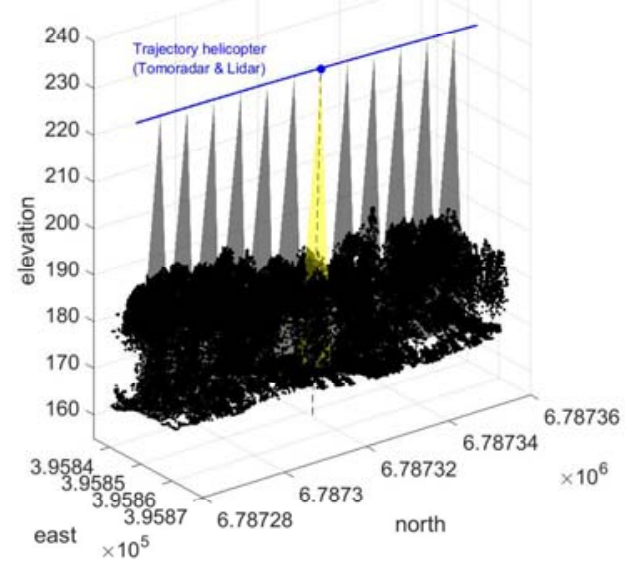

(b)

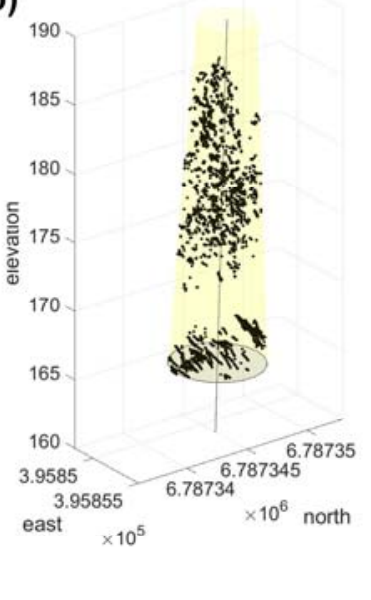

(c)

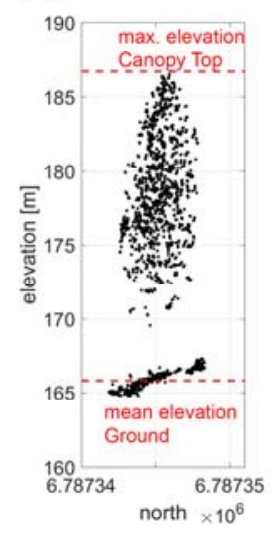

(d)

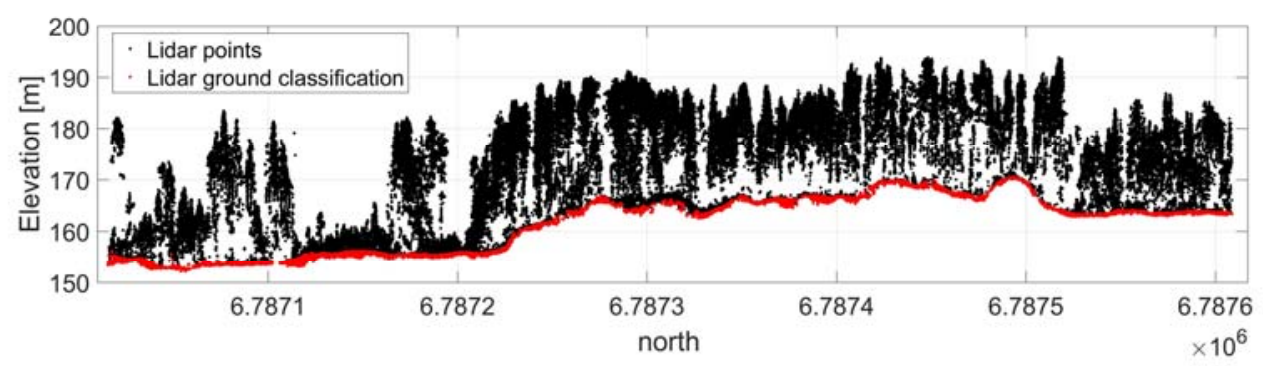

Figure 3. (a) Three-dimensional illustration of the Velodyne Lidar data and the Tomoradar antenna's footprint; (b) three-dimensional view of the Velodyne Lidar points within one footprint cone, whose axis is illustrated by the dashed line; (c) front view of the Velodyne Lidar points within the cone with the reference ground (i.e., the mean elevation of the classified ground point) and canopy elevation (i.e., the maximum elevation of the Lidar point within the cone) used to assess the Tomoradar backscatter signal; (d) front view of all Velodyne Lidar points within the footprint cone and the ground classification (red dots).

\subsubsection{Detection of Ku-Band Ground and Canopy Profiles}

The backscatter signals from the ground and canopy (i.e., upper crown height of dominant plants within the footprint cone) were firstly identified for both polarizations. Then, the energy from the canopy and ground were calculated for each waveform.

A direct Tomoradar peak analysis cannot be applied because of the high noise level of the signals. Therefore, based on the backscatter signal strength, we developed the following signal processing approach to automatically detect, for each waveform, the ground and canopy profile and their corresponding energy. The approach is based on the detection of the abrupt changes of the signal (i.e., increase of the backscatter value in respect to the atmosphere) that characterize the top canopy and the ground. 
The first abrupt change in the range direction between atmosphere and vegetation was classified as canopy point. Therefore, the canopy points are detected as those points with maximum gradient in the waveform using the first derivative of the profile (see green dot in Figure 4). Due to the high frequency noise, the differential function was applied to a filtered signal obtained firstly by a mean-ofmoving average filter and secondly by an optimal fit by a third order polynomial with the Savitzky-Golay differentiation filter. Savitzky-Golay is a lowpass filter smoothing based on local least-squares polynomial approximation [22]. A second abrupt change of the signal can be identified next to the ground. Based on the comparison with Lidar reference measurement, the Tomoradar ground was detected as the flex point between the local maxima and minima of the first derivative by using the second derivative (see yellow dots in Figure 4). The second derivative was also used to determine the threshold of each waveform of the return energy from the canopy and ground. A graphical illustration of the method to derive the ground and canopy profile and the threshold of their corresponding energies is shown in Figure 4 for the HV polarization.
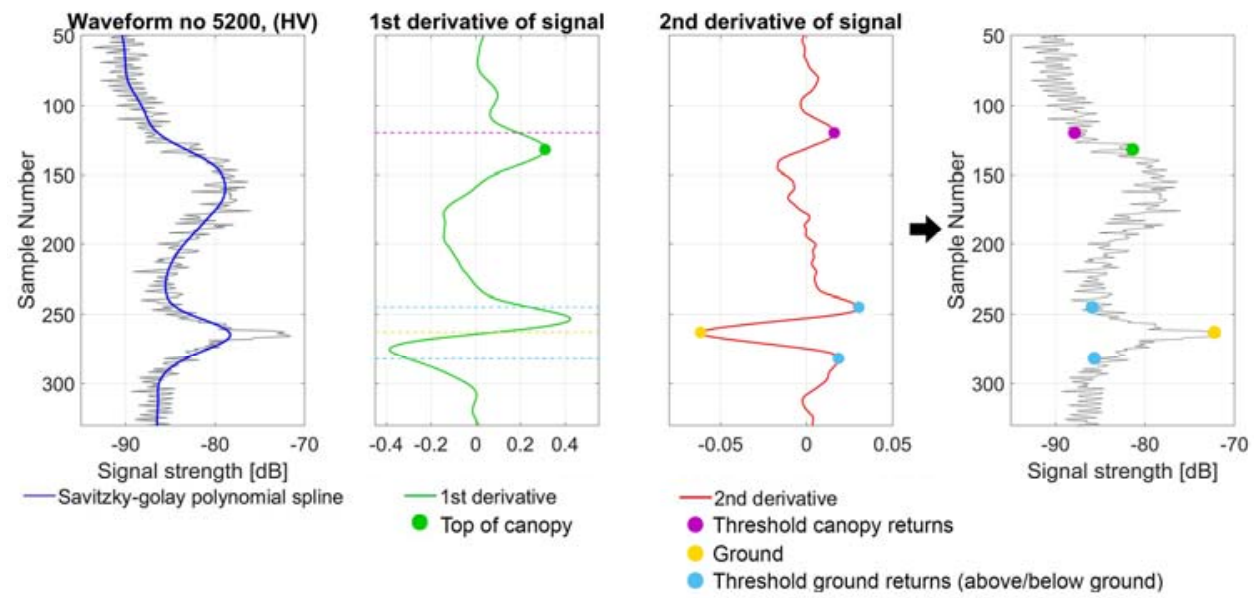

Figure 4. Illustration of the methodology used to derive from the vertical backscatter distribution (waveforms No. 5200) (i) the peak of the canopy top classified as the first strong local maxima of the 1st derivative of the smoothed signal, (ii) the threshold of the canopy returns identified as the local maxima of the 2nd derivative (i.e., inflexion point of the first derivative) above the canopy peak, (iii) the peak of the ground classified as the strongest local minima of the 2nd derivative, and (iv) the threshold of the ground returns defined as the local maxima of the 2 nd derivative (i.e., inflexion point of the first derivative) above and below the ground peak.

\subsubsection{Analysis of the Energy of Ground, Canopy, and Ground Echo Ratio in Comparison with Lidar}

We utilized the Tomoradar data to investigate the physical return of the Ku-band radar and its penetration in complex boreal forest together with Lidar data. The backscatter signal strength from the ground and the vegetation and their energy depend on a wide range of parameters of the sensor and the target object. To identify the main factors that affect the radar returns, we investigated the correlation of the energy of the ground $(\mathrm{dB})$ and the ground echo ratio with Lidar gap fraction and canopy height, antenna incidence angle, and terrain slope.

Additionally, in order to study the distribution of the Ku-band radar signal through the vegetation, we quantified the effect of the vegetation density, defined by the number of Lidar points within the footprint cone. To accomplish this analysis, for each waveform and for both polarizations, we classified 20 intervals at a distance of $1 \mathrm{~m}$ from the Tomoradar canopy profile considering a height threshold of $2 \mathrm{~m}$ above the ground. The average backscatter signal in linear unit within each interval was calculated. For comparison, the average number of Lidar points within every footprint cone from the Tomoradar canopy profile up to $2 \mathrm{~m}$ above the ground was determined. Then, the mean and standard deviation $(\sigma)$ of the backscatter signals and the Lidar points were compared. 
The analyses were performed for the entire Tomoradar vertical profile and in three different sub-areas selected according to the forest density. Area 1 is a homogenous mature conifer forest, and most of the trees have a similar range of heights; Area 2 is similar to Area 1 with additional presence of small trees; Area 3 is composed by dense and homogeneous layer of young trees and bushes.

\subsubsection{Validation of Signal Processing Method: Comparison of Waveform Features with Canopy and} Terrain Elevation

The accuracy of our approach to derive the Tomoradar ground and canopy profiles was evaluated by means of linear regression between the elevation of the ground and canopy profile derived by the Tomoradar backscatter signal and Lidar. Moreover, the elevation difference between the estimated Tomoradar ground and canopy profile and the Lidar reference data was calculated. By knowing the height of the Tomoradar ground and canopy profile, the information about the Tomoradar canopy height was derived for both polarizations and compared with the Lidar measurements. As main metrics, the mean, standard deviation $(\sigma)$ and root mean square error (RMSE) for the canopy height difference were extracted.

\section{Results}

\subsection{Quantitative Analyses of the Ku-Band Backscatter Signal Penetration}

A visual comparison between the Tomoradar waveform and the histogram of the corresponding Lidar points within the footprint cone is shown in Figure 5 for two waveforms that hit a dense bush and an area with an adult tree, respectively. The shape of the ground, tree, and bush can be observed both in the Tomoradar signal peak and Lidar histogram. Moreover, it can be observed that the mean ground level and the maximum elevation extracted from Velodyne Lidar measurements (i.e., the dash lines) coincides with the abrupt change of the signal shape that represent the ground and canopy reflection, respectively.
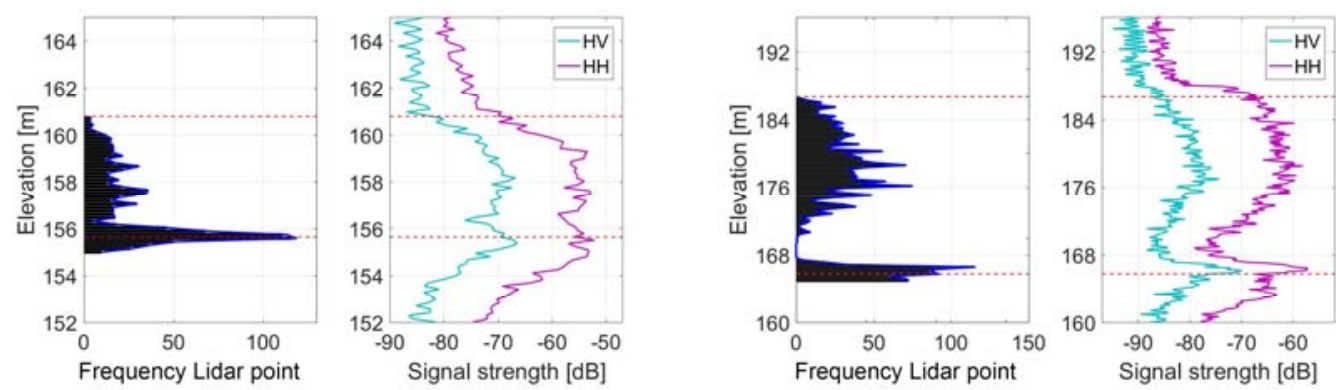

Figure 5. Comparison between the Tomoradar waveform, for both polarizations, and the histogram of the corresponding Lidar points within the footprint cone. The comparison is provided for a bush (left side) and high tree (right side). The red dash lines are the reference ground and canopy elevation extracted from Velodyne Lidar measurements. The location of those waveforms (no. 2164, and no. 5300) are shown in Figure 2 by dashed lines.

According to our method, to automatically detect the abrupt changes of the signal, the ground and canopy points and the thresholds of their returns are shown in Figure 6a for the entire profile and for both polarizations. The ground and canopy backscatter energy expressed in $\mathrm{dB}$ reveal similar trends for the two polarizations (Figure 7a), but the co-polarized returns of the ground and canopy over the entire profile are on average $15 \mathrm{~dB}$ and $16 \mathrm{~dB}$ higher than the cross-polarized (Table 2). A strong correlation exists between the cross- and co-polarized energy of the ground and canopy with a coefficient of determination $R^{2}=0.80$ and $R^{2}=0.69$, respectively. As shown in the Figure 7 , for both polarizations the magnitude of ground and canopy backscatter are quite comparable. However, for the entire profile, the cross-polarized energy is, on average, $-59.2 \mathrm{~dB}$ for the canopy and $-60.7 \mathrm{~dB}$ for the 
ground, whereas for the co-polarization, the energy of the canopy is, on average, $2.3 \mathrm{~dB}$ higher than the energy of the ground. The ground echo ratio for the entire profile is shown in Figure $7 \mathrm{~b}$ for both polarizations, and the corresponding values for the entire profile and for the three selected areas are listed in Table 3.
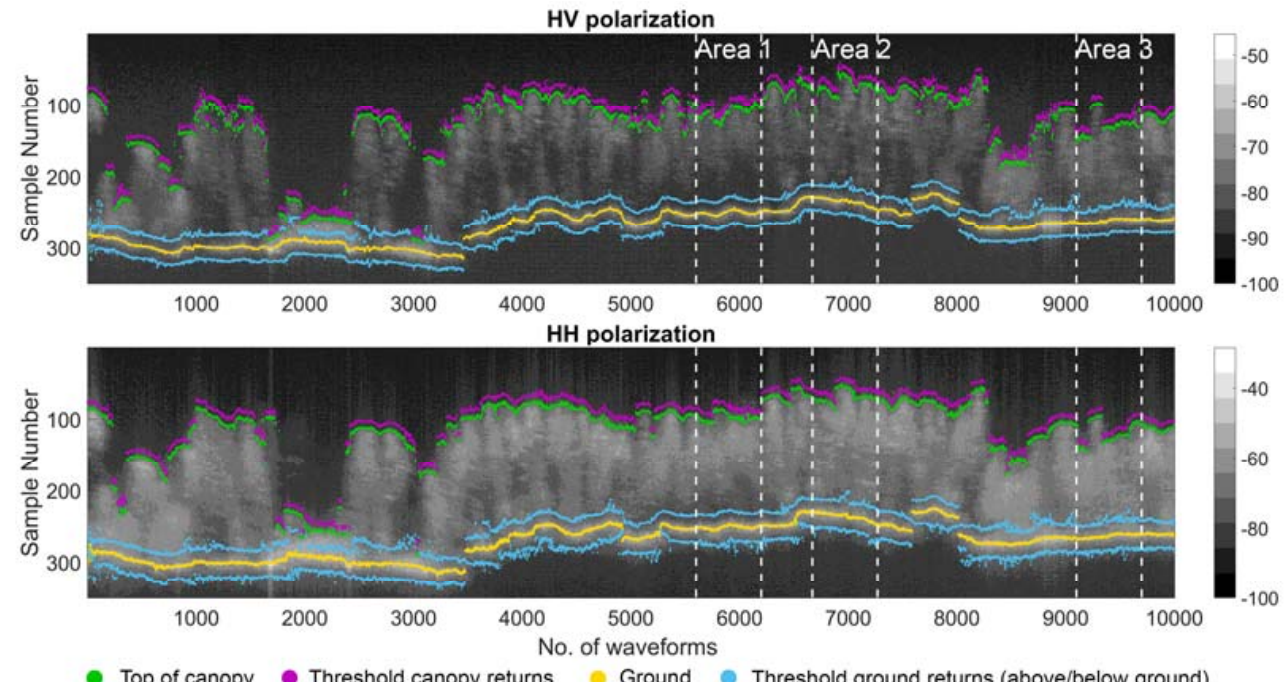

Figure 6. Cross- and co-polarized Tomoradar vertical profile in grey scale with the estimated canopy (green dots) and ground (yellow dots) profiles, and the threshold of the returns above the canopy (magenta dots) and above and below the ground (light blue dots) points for each waveforms. The weight dash lines represent the selected sub-areas.

(a)
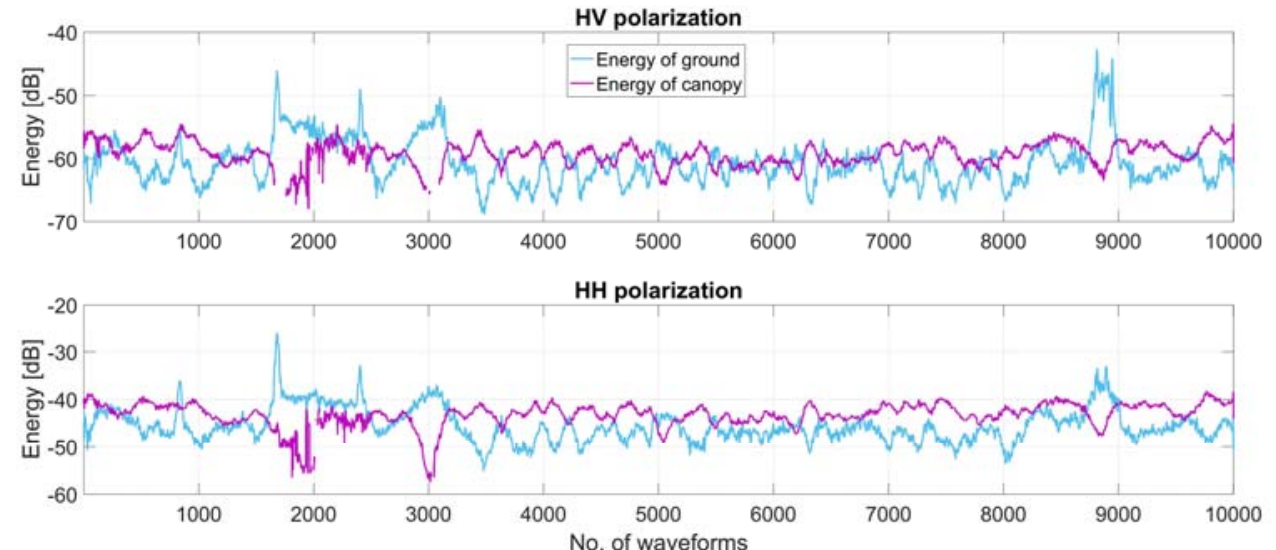

(b)

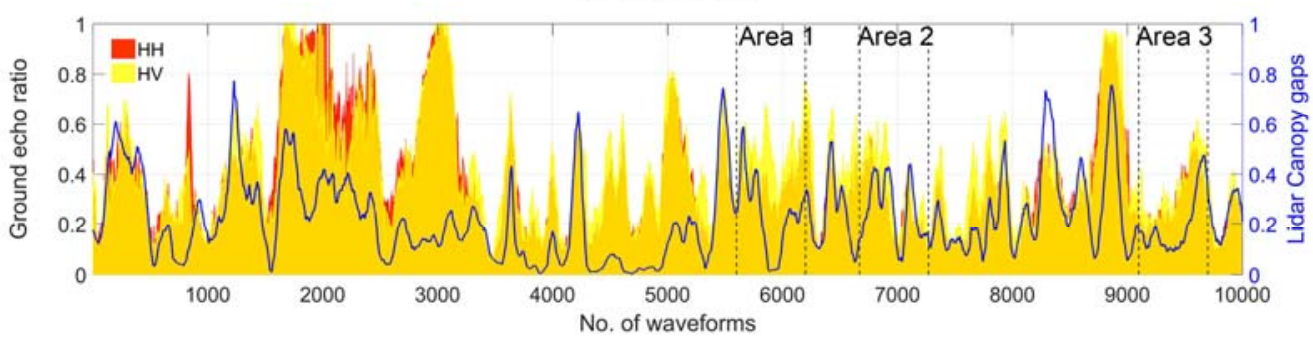

Figure 7. (a) Energy of the ground and energy of the canopy (i.e., ground and canopy integrated backscatter expressed in $\mathrm{dB}$ ), for both polarizations; (b) the ground echo ratio for the two polarizations and the estimated canopy gaps (blue line) according to the Velodyne Lidar points.

Quantitative analyses of the ground backscatter signal strength and its echo ratio are performed by linear regression with the Lidar gap fraction and canopy height (Figure 8 ). The backscatter signal 
strength from the ground exhibits a correlation value of $\mathrm{R}^{2}=0.29(\mathrm{HV})$ and $\mathrm{R}^{2}=0.22(\mathrm{HH})$ with respect to the number of Lidar canopy gaps, for both polarizations. A similar relationship is detected between the ground echo ratio and the Lidar canopy gaps $\left(R^{2}=0.23\right.$, for the $H V$ and $R^{2}=0.19$, for the $\mathrm{HH}$ polarization) and canopy height $\left(\mathrm{R}^{2}=0.27\right.$, for the $\mathrm{HV}$ and $\mathrm{R}^{2}=0.37$, for the $\mathrm{HH}$ polarization). As expected, the ground echo ratio has negative correlation with the canopy height and positive correlation with the canopy gaps. Due to the nadir measurement geometry, the strongest ground backscatter signals and echo ratios close to one happened in areas without vegetation cover, for both polarized channels. The ground echo ratio of the entire profile is, on average, 0.42 and 0.38 for the $\mathrm{HV}$ and $\mathrm{HH}$ polarization, respectively. In the Area1, characterized by the absence of bushes or young trees and a low number of stems points, the ground echo ratio is, on average, $0.49(\mathrm{HV})$ and $0.36(\mathrm{HH})$. In the Area 2 and 3, the presence of bushes and young trees reduced the echo ratio by approximately $10 \%$ for both polarizations (Table 3 ).
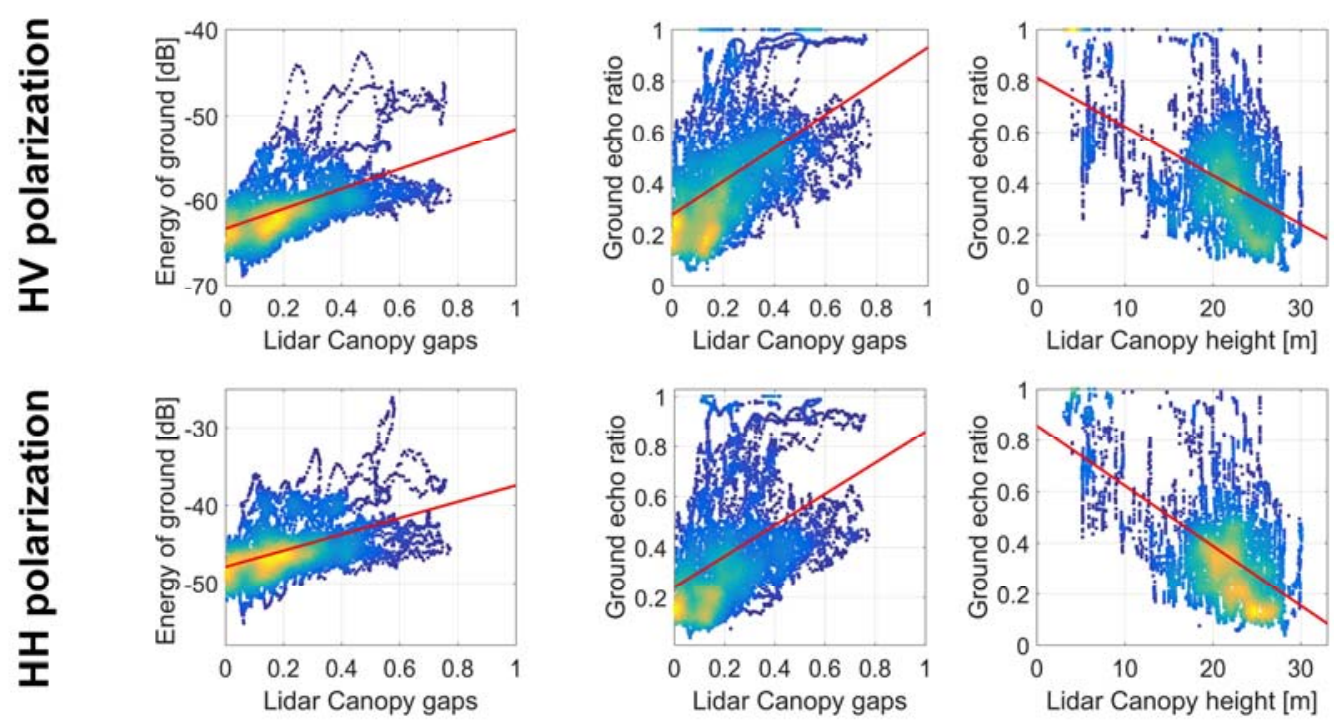

Figure 8. Scatter plots between the energy of the ground and the ground echo ratio with respect to the Lidar canopy gaps and canopy height, for the two polarizations.

The vegetation point density, defined by the number of Lidar points of the vegetated areas, affects the signal returns, expressed in linear units, from the object, as illustrated in Figure 9. The higher the number of Lidar points, the higher the signals are. In addition, the trend of the average signals through the vegetation corresponds to the distribution of the average number of Lidar points. This analysis suggests that both sensors similarly respond to forest vertical parameters (i.e., leaves, branches, and stems).

Table 2. For both polarizations, the backscatter energy expressed in $\mathrm{dB}$ of the ground and canopy for the entire profile and for the three selected areas.

\begin{tabular}{|c|c|c|c|c|c|c|c|c|c|}
\hline \multirow{3}{*}{ Polar. } & \multicolumn{2}{|c|}{$\begin{array}{c}\text { Energy } \\
\text { Entire Profile }\end{array}$} & \multicolumn{4}{|c|}{$\begin{array}{c}\text { Energy of Ground } \\
\text { Selected Area ( } \sim 36 \mathrm{~m} \text { Profile) }\end{array}$} & \multicolumn{3}{|c|}{$\begin{array}{c}\text { Energy of Canopy } \\
\text { Selected Area ( } \sim 36 \mathrm{~m} \text { Profile) }\end{array}$} \\
\hline & Ground & Canopy & Area 1 & \multicolumn{2}{|c|}{ Area 2} & Area 3 & Area 1 & Area 2 & Area 3 \\
\hline & Mean $\sigma$ & Mean $\sigma$ & Mean $\sigma$ & Mean & $\sigma$ & Mean $\sigma$ & Mean $\sigma$ & Mean $\sigma$ & Mean $\sigma$ \\
\hline $\mathrm{HV}$ & -60.73 .5 & -59.21 .8 & -61.21 .3 & -61.8 & 2.1 & -61.71 .6 & -61.00 .7 & -59.01 .0 & -58.71 .0 \\
\hline $\mathrm{HH}$ & -45.53 .5 & -43.22 .5 & -46.91 .0 & -47.1 & 1.8 & -46.21 .4 & -44.31 .0 & -42.21 .1 & $\begin{array}{lll}-42.1 & 1.1\end{array}$ \\
\hline
\end{tabular}


Table 3. For both polarizations, the ground echo ratio for the entire profile and for three selected areas.

\begin{tabular}{ccccccccccc}
\hline & $\begin{array}{c}\text { Ground Echo Ratio } \\
\text { Entire Profile }\end{array}$ & \multicolumn{5}{c}{$\begin{array}{c}\text { Ground Echo Ratio } \\
\text { Selected Area ( 36 m Profile) }\end{array}$} \\
\hline \multirow{2}{*}{ Polarized Channel } & Mean & $\sigma$ & \multicolumn{2}{c}{ Area 1 } & \multicolumn{2}{c}{ Area 2 } & \multicolumn{2}{c}{ Area 3 } \\
\cline { 4 - 10 } & & & Mean & $\sigma$ & Mean & $\sigma$ & Mean & $\sigma$ \\
\hline HV & 0.42 & 0.22 & 0.49 & 0.09 & 0.36 & 0.14 & 0.35 & 0.12 \\
HH & 0.38 & 0.23 & 0.36 & 0.08 & 0.26 & 0.11 & 0.28 & 0.11 \\
\hline
\end{tabular}

(a)
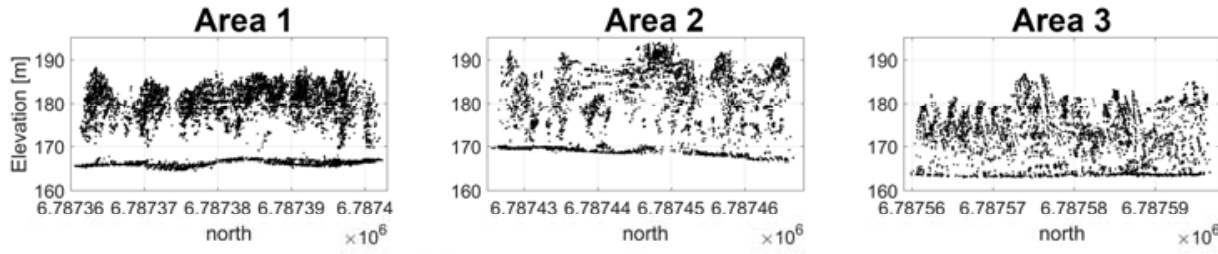

(b)

(c)
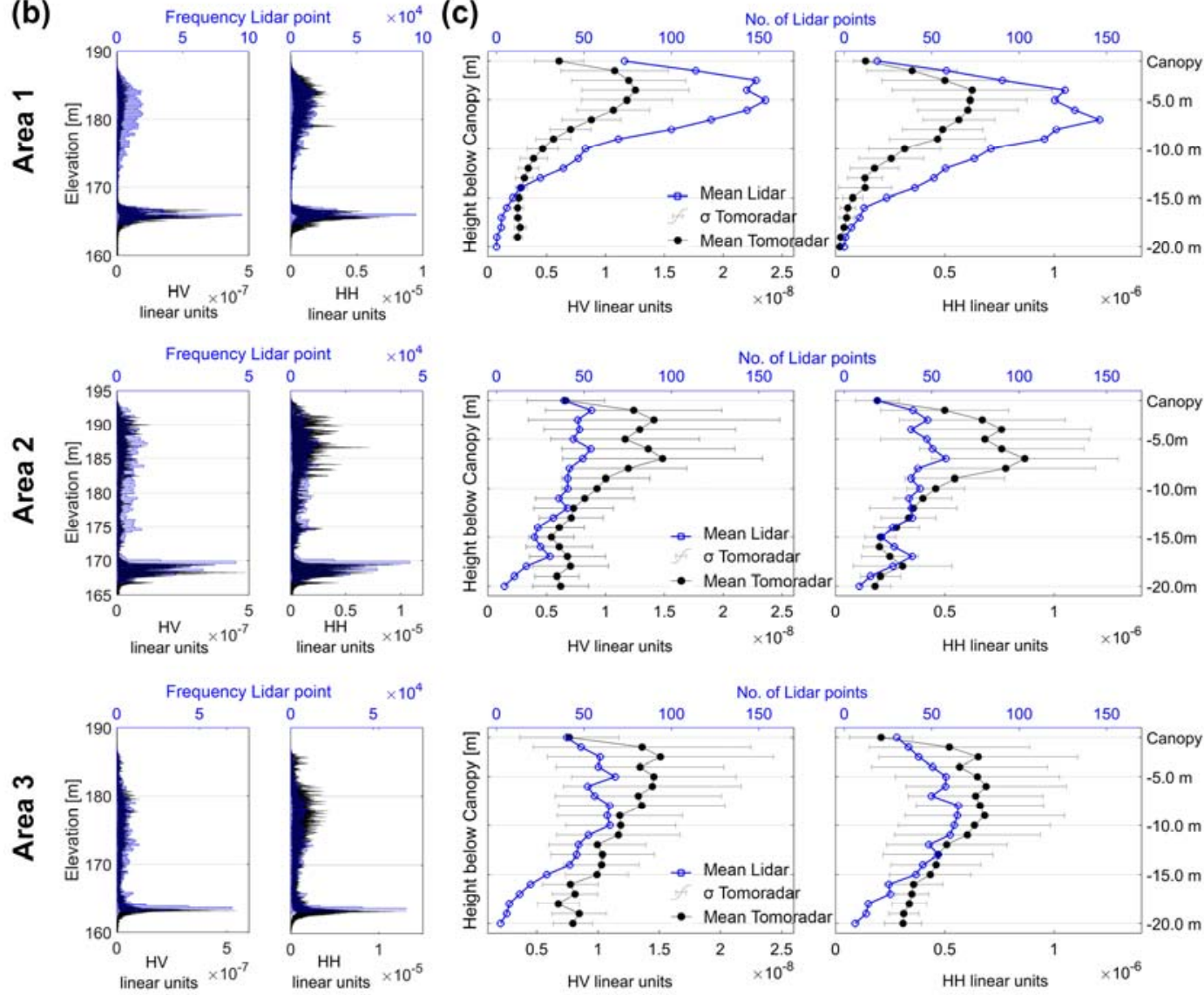

Figure 9. (a) The Lidar point cloud for the three sub-areas; (b) for the three sub-areas and for both polarizations the 600 waveforms ( $\sim 36 \mathrm{~m})$, expressed in linear units, and the histogram of the corresponding Lidar points within the footprint cone; (c) the mean backscatter with standard deviation error bars expressed in linear units of Tomoradar vertical profiles with respect to the depth below the canopy every $1 \mathrm{~m}$, and a comparison with the mean number of Lidar points within the volume $1 \mathrm{~m}$ represents. Twenty intervals below the canopy with a height greater than $2 \mathrm{~m}$ above the ground were considered.

\subsection{Estimation of Tomoradar Ground and Canopy Elevation Accuracy}

In order to validate our approach to detect the ground and canopy layer from the backscatter signal analysis, we estimated the accuracy of the corresponding ground and canopy elevation of 
the Tomoradar signal peak with the Lidar measurements. The ground elevations derived by the two polarizations are strongly correlated $\left(R^{2}=0.99\right)$ with an average elevation difference of $-0.173 \mathrm{~m}$ $(\sigma=0.284 \mathrm{~m})$. Tomoradar and Velodyne accuracy are similar with respect to Riegl (Table 4).

Table 4. Elevation difference between the estimated Tomoradar ground and canopy profile for the two polarizations and the Lidar data.

\begin{tabular}{|c|c|c|c|c|c|c|c|c|c|c|}
\hline \multirow{3}{*}{ Data } & \multicolumn{10}{|c|}{ Elevation Difference [m] } \\
\hline & \multicolumn{5}{|c|}{ Ground } & \multicolumn{5}{|c|}{ Canopy } \\
\hline & Mean & $\sigma$ & Median & RMSE & $\mathbf{R}^{2}$ & Mean & $\sigma$ & Median & RMSE & $\mathbf{R}^{2}$ \\
\hline \multicolumn{11}{|l|}{ Tomoradar } \\
\hline HH-HV & -0.173 & 0.284 & -0.140 & 0.333 & 0.997 & 1.544 & 2.910 & 0.842 & 3.294 & 0.849 \\
\hline \multicolumn{11}{|l|}{ Tomoradar-Lidar } \\
\hline HV-Velodyne & -0.033 & 0.440 & -0.112 & 0.441 & 0.993 & -0.584 & 2.422 & -0.586 & 2.492 & 0.930 \\
\hline HH-Velodyne & -0.207 & 0.491 & -0.281 & 0.533 & 0.991 & 1.354 & 3.430 & 0.334 & 3.687 & 0.858 \\
\hline HV-Riegl & -0.167 & 0.339 & 0.159 & 0.378 & 0.996 & - & - & - & - & - \\
\hline HH-Riegl & -0.006 & 0.403 & -0.003 & 0.403 & 0.994 & - & - & - & - & - \\
\hline \multicolumn{11}{|l|}{ Riegl-Velodyne } \\
\hline Velodyne-Riegl & 0.201 & 0.341 & 0.282 & 0.395 & 0.996 & - & - & - & - & - \\
\hline
\end{tabular}

A visual comparison between the estimated Tomoradar canopy profiles (HH and $\mathrm{HV}$ ) and Lidar is shown in Figure 10. According to the figure, the estimated cross- and co-polarized canopy profiles follow the canopy top derived by Lidar data. However, different penetration rate for the two polarizations can be perceived. The linear relationship between the cross- and co-polarized canopy elevation is $\mathrm{R}^{2}=0.84$, but with an elevation difference of $1.54 \mathrm{~m}$ and a RMSE of $3.29 \mathrm{~m}$ on average. The canopy elevation of the cross-polarized profile is slightly lower than that of the Lidar, on average by $-0.58 \mathrm{~m}$. Contrarily, the co-polarized canopy profile is, on average, $1.35 \mathrm{~m}$ higher than the Lidar. Despite the evident different capability of the two polarizations to penetrate the canopy gaps, the accuracy of the Tomoradar canopy elevation of the two polarizations and their differences is not significantly correlated to the Lidar canopy gaps.

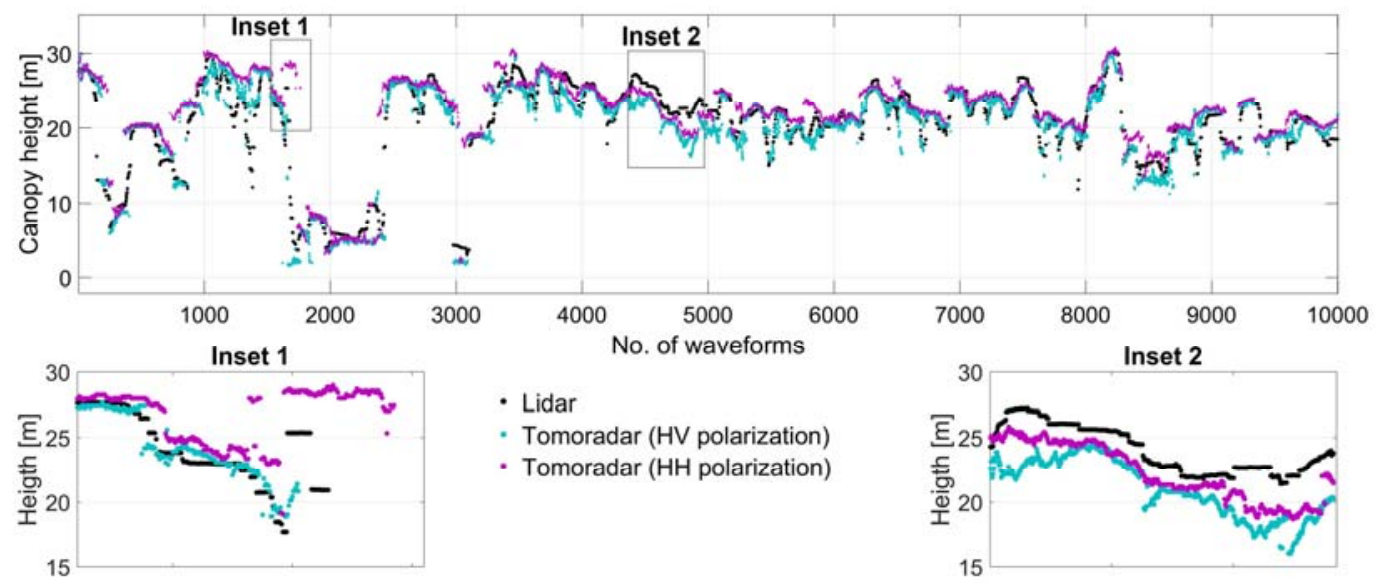

Figure 10. Canopy height derived by the Tomoradar with the reference Lidar canopy height.

The Tomoradar forest height (HH and HV polarization) was calculated from the elevation difference between the elevation of the ground and canopy profiles, and the accuracy has been assessed through the comparison with Lidar. In agreement with the previous results about the accuracy of the Tomoradar ground and canopy elevation, the forest height derived by the co-polarized channel is higher than the Lidar, on average, by $1.56 \mathrm{~m}$, whereas the cross-polarization underestimates the 
canopy height of $0.38 \mathrm{~m}$. However, considering the canopy points with an elevation greater than $5 \mathrm{~m}$ from the Lidar reference $(4.1 \%$ and $9.5 \%$ for the $\mathrm{HV}$ and $\mathrm{HH}$, respectively) as outliers, the Tomoradar canopy height is, on average, lower than the Lidar canopy height of $0.47 \mathrm{~m}$ for the cross polarization, whereas the co-polarization is higher than $0.68 \mathrm{~m}$, with an RMSE of $1.69 \mathrm{~m}$ and $1.76 \mathrm{~m}$ for the crossand co-polarization, respectively.

\section{Discussion}

The use of Ku-band profiling radar system has not been tested on forests before. The compact size and light weight of the antenna allowed us to mount the system on a helicopter and to compare the results with simultaneous Lidar measurements. Our goal to collect Tomoradar and Lidar data simultaneously restricted the Tomoradar recording to nadir direction along the trajectory with a few meters swath width. The major issue in utilizing Lidar data to support the investigation of the Tomoradar waveforms is the footprint mismatch. Therefore, in this study, we modelled the Tomoradar footprint cones to determine all Lidar points within the cones. As the total weight of the Tomoradar system is less than $5 \mathrm{~kg}$, it is, in principle, possible to install it even on unmanned aerial vehicles [19] and use it for off-nadir recordings.

We found that the Tomoradar waveforms (i.e., the backscatter signal strength) show many similarities with the Lidar point distributions (see Figure 5). The backscatter signal strength of the ground is, overall, comparable to the scattering energy over the entire vegetation canopy for both polarisations. However, in some waveforms there is a strong reflection from the tree canopy (see the yellow dots in Figure 2). Moreover, in presence of bushes with a height of a few meters, the ground peak cannot be easily distinguished from the vegetation above.

In this study, we focused on the ground and canopy profile and their corresponding backscatter energies. The automatic detection of ground and canopy top points for each waveform is not straightforward due to the high noise of the signal that has prevented a direct peak detection. We developed a methodology based on the automatic detection of the abrupt changes of the signal shape using the first and second derivative of the signal. The detection of those points was performed for each waveform on a smoothed signal by a moving average filter and a polynomial low-pass filter. The filter window size, in the range direction, was chosen as a compromise between the need of filtering the noise and the possibility to distinguish the signal of the ground from the one derived by the bushes above. However, the choice of the filter window size can slightly affect the accuracy of the peak detection and the details of the signals. The detection of the ground peaks was derived with higher accuracy, for both polarizations, since the ground provided has, in general, clear and higher backscatter signals than the vegetation above. The detection of the thresholds of canopy and ground returns were more affected by the smoothed signal, especially in the presence of low dense bushes (see Figure 5), i.e., when the signal of the ground is not stronger than the vegetation and is with sloped terrain due to multiple high reflections from the ground. The filter window size could have affected the detection of the top of canopy points as well, because this is classified for each waveform as the first local maxima of the first derivative of the smoothed signal. The presence of high noise in the atmosphere, also after the noise filter, could produce several peaks before the canopy top. A detection of the wrong peak can generate meters of differences considering a sampling signal of $15 \mathrm{~cm}$.

The cross-polarized signal is normally weaker than the co-polarized and this can vary according to the forest canopy and species, signal frequency, and acquisition geometry. In our study, we found that the ground co-polarized backscatter signals strength in $\mathrm{dB}$ was stronger than the cross-polarized backscatter signals strength by, on average, $15 \mathrm{~dB}$. For both polarizations, the total canopy backscatter energy was somewhat stronger than the ground returns. Indeed, for the three selected areas (i.e., a homogeneous mature forest, a mature forest with young trees, and young trees with dense vegetation layers below the canopy) the average energy of the canopy exceeded the ground returns, for both polarizations. A ground echo ratio close to 0.5 was identified only for the cross-polarized signal in Area 1 characterized by adult trees without sub-vegetation layers. The entire profile is characterized 
by very few ground areas free of vegetation as visible in the Velodyne Lidar points within the footprint cone (see Figure 3d). However, for those open areas where there are only ground echoes within the radar cone, the ground echo ratio equal to one doesn't correspond to the highest Lidar canopy gaps likely due to the classification of Lidar ground points. Despite this, a higher number of Lidar ground points and, therefore, more gaps between vegetation increased the energy of the ground and its echo ratio, as is visible in the scatter plot in Figure 8. For the same reason, the energy of the ground and the ground echo ratio were inversely proportional to the height of the canopy above. Additionally, we quantified that the presence of sub-vegetation layers like bushes of young trees within the antenna's footprint attenuated the ground echo ratio by approximately $10 \%$ for both polarizations.

The average signal returns expressed in linear units for three selected areas showed close agreement with the branch distribution through the canopy, stems, and sub-layers vegetation represented by the numbers of Lidar points within the Tomoradar footprint cone. Those results are a confirmation that waveform profile strongly depends on the canopy vertical structure such as canopy height and forest density. Moreover, the Ku-band penetration capability, primarily driven by canopy gaps, is comparable with Lidar.

The variation of the ground echo ratio and energy of the ground with incidence angle and slope gradient should be further investigated in further studies. In our study, the slope was, on average, close to zero with a standard deviation of $9^{\circ}$, and the incidence angle was practical nadir with a maximum angle of $5.9^{\circ}$. We thus cannot comment on the observations published by [19] about the effect of blurred ground reflection due to the increase of the incidence angle.

In comparison with the Velodyne Lidar reference data, we found that the Tomoradar cross-polarized backscatter signals penetrated deeper through the canopy gaps than the co-polarized signal. This is visible in the canopy height profile, as illustrated in Figure 10, and demonstrated by the higher mean value of the ground echo ratio (see Table 3). Additionally, the cross-polarized backscatter signals were less affected by trees located at the edge of the antenna footprint cone (see Inset 1 in Figure 10). The divergence of footprint between the two polarizations could be due to the antenna designer. The elevation difference between $\mathrm{HH}$ and $\mathrm{HV}$ canopy profiles possibly originated from the orientation of the scattered leaves. Quantifying the accuracy of the estimated Tomoradar canopy height in comparison to the reference Velodyne Lidar data, for both polarizations the RMSE is lower than $2 \mathrm{~m}$ if we consider the Tomoradar canopy points with an elevation greater than $5 \mathrm{~m}$ from the Lidar reference as outliers. On average, the $\mathrm{HH}$ polarization overestimates the elevation of the canopy profile by $0.68 \mathrm{~m}$, whereas the HV polarization underestimates by $0.47 \mathrm{~m}$. These results partially disagree with the qualitative observation of [19], according to which both polarized Tomoradar data underestimate the canopy height. However, since Lidar measurements may fail to sample the tops of relatively broad trees, especially for hardwood and mixed forests [23], we cannot completely rely on the elevation comparison with the tree top of the Velodyne data. A good agreement between the canopy height from Lidar, cross- and co-polarization, is observed for high single trees, whereas a different height variation of dense vegetation produces greater differences, mainly due to the capability of cross-polarization to more deeply penetrate the canopy gaps. In addition, the detection of single Lidar canopy points with an elevation significantly higher (see Inset 2 in Figure 10) than the Tomoradar canopy profiles, for both polarizations, suggests possible georeferencing errors or errors related to the modelling of the footprint cone used to define the reference Lidar data. Further investigations in relation to dominant height from field reference data and trees species are necessary. Contrarily, the elevation of the Tomoradar ground profile in comparison with the reference Riegl Lidar data revealed high accuracy, with an RMSE of $0.34 \mathrm{~m}$ and $0.40 \mathrm{~m}$ for the co-and cross-polarization, respectively. This is a promising result for future measurements in areas in which no ground surface information is available or, as a possible complementary technique to Lidar, in presence of very dense canopy. 


\section{Conclusions}

The study focused on the analysis of a helicopter-borne profiling radar backscatter over boreal forest. The Finnish Geospatial Research Institute designed the Ku-band radar system, called Tomoradar, as a tool for interpreting satellite data and as a possible complementary technique to Lidar for deriving forest information. To support the Tomoradar analysis, the radar waveforms and backscatter signals were compared with the Lidar measurement acquired simultaneously by means of a lightweight Lidar sensor.

Despite the noisy and smeared-out signals, the developed waveform signal processing approach was successful in detecting the top of the forest canopy and the ground surface. The Ku-band ground integrated backscatter in cross-polarization is approximately $15 \mathrm{~dB}$ lower than that of the co-polarization for the same target. The radar penetration is closely correlated with the forest gap fraction, but for high-biomass boreal forests, the canopy return dominates over the ground return. The ground echo ratio is a function of canopy gaps and canopy height, whereas the distribution of the signal trough the vegetation reflects the vegetation density. We conclude that profiling radar is very useful for understanding signal contributions, and an extension to other frequencies is recommended for interpreting current spaceborne SAR sensors. Thanks to the combination of the Tomoradar with GPS/IMU data, Tomoradar has potential for canopy profiling and terrain height estimation under all weather conditions.

Acknowledgments: The research leading to these results has received funding from the European Community's Seventh Framework Programme ([FP7/2007-2013]) under the Advanced_SAR project (grant agreement No. 606971).

Author Contributions: Livia Piermattei executed all the analyses and wrote most of the paper; Livia Piermattei, Markus Hollaus, and Wolfgang Wagner planned the analyses; Milutin Milenković and Raphael Quast shaped significant ideas for the analyses; Milutin Milenković additionally assisted with the analyses; Norbert Pfeifer reviewed the content and offered substantial improvement for this paper; Yuwei Chen and Teemu Hakala designed the Tomoradar hardware system and collected the data; Juha Hyyppä and Mika Karjalainen conceived and designed the Tomoradar experiment; Wolfgang Wagner played a strong role in the scientific supervision and the refinement of the focus of the paper.

Conflicts of Interest: The authors declare no conflict of interest.

\section{References}

1. Ridder, R.M. Global Forest Resources Assessment 2010: Options and Recommendations for a Global Remote Sensing Survey of Forests. FAO Forestry Working Paper 141. 2007. Available online: http://www.fao.org/3/a-ai074e. pdf (accessed on 20 September 2017).

2. Spies, T.A.; Spies, T.A. Forest structure: A key to the ecosystem. Northwest Sci. 1998, 72, 34-36.

3. Hurtt, G.C.; Dubayah, R.; Drake, J.; Moorcroft, P.R.; Pacala, S.W.; Blair, J.B.; Fearon, M.G. Beyond potential vegetation: Combining lidar data and a height-structured model for carbon studies. Ecol. Appl. 2004, 14, 873-883. [CrossRef]

4. Drake, J.B.; Dubayah, R.O.; Clark, D.B.; Knox, R.G.; Blair, J.B.; Hofton, M.A.; Chazdone, R.L.; Weishampelf, J.F.; Prince, S. Estimation of tropical forest structural characteristics using large-footprint lidar. Remote Sens. Environ. 2002, 79, 305-319. [CrossRef]

5. Kellndorfer, J.; Walker, W.; Pierce, L.; Dobson, C.; Fites, J.A.; Hunsaker, C.; Clutter, M. Vegetation height estimation from shuttle radar topography mission and national elevation datasets. Remote Sens. Environ. 2004, 93, 339-358. [CrossRef]

6. Andersen, H.E.; Reutebuch, S.E.; McGaughey, R.J. Active remote sensing. In Computer Applications in Sustainable Forest Management; Springer: Dordrecht, The Netherlands, 2006; pp. 43-66.

7. Devaney, J.; Barrett, B.; Barrett, F.; Redmond, J.; O'Halloran, J. Forest Cover Estimation in Ireland Using Radar Remote Sensing: A Comparative Analysis of Forest Cover Assessment Methodologies. PLoS ONE 2015, 10, e0133583. [CrossRef] [PubMed]

8. Perko, R.; Raggam, H.; Deutscher, J.; Gutjahr, K.; Schardt, M. Forest assessment using high resolution SAR data in X-band. Remote Sens. 2011, 3, 792-815. [CrossRef] 
9. Balzter, H.; Rowland, C.S.; Saich, P. Forest canopy height and carbon estimation at Monks Wood National Nature Reserve, UK, using dual-wavelength SAR interferometry. Remote Sens. Environ. 2007, 108, 224-239. [CrossRef]

10. Soja, M.J.; Persson, H.; Ulander, L.M. Estimation of forest height and canopy density from a single InSAR correlation coefficient. IEEE Geosci. Remote Sens. Lett. 2015, 12, 646-650. [CrossRef]

11. Solberg, S.; Astrup, R.; Bollandsås, O.M.; Næsset, E.; Weydahl, D.J. Deriving forest monitoring variables from X-band InSAR SRTM height. Can. J. Remote Sens. 2010, 36, 68-79. [CrossRef]

12. Karjalainen, M.; Kankare, V.; Vastaranta, M.; Holopainen, M.; Hyyppä, J. Prediction of plot-level forest variables using TerraSAR-X stereo SAR data. Remote Sens. Environ. 2012, 117, 338-347. [CrossRef]

13. Schmitt, M.; Brück, A.; Schönberger, J.; Stilla, U. Potential of airborne single-pass millimeterwave InSAR data for individual tree recognition. In Proceedings of the 33rd Wissenschaftlich-Technische Jahrestagung der DGPF, Freiburg, Germany, 27 February-1 March 2013; pp. 427-436.

14. Tebaldini, S.; Ferro-Famil, L. High resolution three-dimensional imaging of a snowpack from ground-based SAR data acquired at $X$ and $\mathrm{Ku}$ band. In Proceedings of the 2013 IEEE International Geoscience and Remote Sensing Symposium (IGARSS), Melbourne, Australia, 21-26 July 2013; pp. 77-80.

15. King, J.; Kelly, R.; Kasurak, A.; Duguay, C.; Gunn, G.; Rutter, N.; Watts, T.; Derksen, C. Spatio-temporal influence of tundra snow properties on Ku-band (17.2 GHz) backscatter. J. Glaciol. 2015, 61, 226. [CrossRef]

16. Rott, H.; Cline, D.; Duguay, C.; Essery, R.; Haas, C.; Macelloni, G.; Yueh, S. CoReH2O-A Ku-and X-band SAR mission for snow and ice monitoring. In Proceedings of the 7th European Conference on Synthetic Aperture Radar (EUSAR), Friedrichshafen, Germany, 2-5 June 2008; pp. 1-4.

17. Hyyppä, J.; Hallikainen, M. A helicopter-borne 8-channel ranging scatterometer for remote sensing, Part II: Forest Inventory. IEEE Trans. Geosci. Remote Sens. 1993, 31, 170-179. [CrossRef]

18. Morrison, K.; Bennett, J.; Solberg, S. Ground-based C-band tomographic profiling of a conifer forest stand. Int. J. Remote Sens. 2013, 34, 7838-7853. [CrossRef]

19. Chen, Y.; Hakala, T.; Karjalainen, M.; Feng, Z.; Tang, J.; Litkey, P.; Hyyppä, J. UAV-Borne Profiling Radar for Forest Research. Remote Sens. 2017, 9, 58. [CrossRef]

20. Feng, Z.; Chen, Y.; Hakala, T.; Hyyppä, J. Range calibration of airborne profiling radar used in forest inventory. In Proceedings of the 2016 IEEE International Geoscience and Remote Sensing Symposium (IGARSS), Beijing, China, 10-15 July 2016; pp. 6672-6675.

21. Pfeifer, N.; Mandlburger, G.; Otepka, J.; Karel, W. OPALS-A framework for Airborne Laser Scanning data analysis. Environ. Urban Syst. 2014, 45, 125-136. [CrossRef]

22. Savitzky, A.; Golay, M.J. Smoothing and differentiation of data by simplified least squares procedures. Anal. Chem. 1964, 36, 1627-1639. [CrossRef]

23. Banskota, A.; Wynne, R.H.; Johnson, P.; Emessiene, B. Synergistic use of very high-frequency radar and discrete-return lidar for estimating biomass in temperate hardwood and mixed forests. Ann. For. Sci. 2011, 68, 347-356. [CrossRef]

(C) 2017 by the authors. Licensee MDPI, Basel, Switzerland. This article is an open access article distributed under the terms and conditions of the Creative Commons Attribution (CC BY) license (http:// creativecommons.org/licenses/by/4.0/). 